\title{
Squirt flow due to interfacial water films in hydrate bearing sediments
}

\author{
Kathleen Sell $^{1,2}$, Beatriz Quintal ${ }^{3}$, Michael Kersten ${ }^{1}$, and Erik H. Saenger ${ }^{4,5}$ \\ ${ }^{1}$ Institute of Geosciences, Johannes Gutenberg-University Mainz, Mainz, Germany \\ ${ }^{2}$ Institute for Geothermal Resource Management, Bingen, Germany \\ ${ }^{3}$ Institute of Earth Sciences, University of Lausanne, Lausanne, Switzerland \\ ${ }^{4}$ International Geothermal Centre, Bochum University of Applied Sciences, Bochum, Germany \\ ${ }^{5}$ Institute of Geology, Mineralogy and Geophysics, Ruhr University Bochum, Bochum, Germany
}

Correspondence: Kathleen Sell (sell@uni-mainz.de)

Received: 12 September 2017 - Discussion started: 25 September 2017

Revised: 16 December 2017 - Accepted: 2 May 2018 - Published: 30 May 2018

\begin{abstract}
Sediments containing gas hydrate dispersed in the pore space are known to show a characteristic seismic anomaly which is a high attenuation along with increasing seismic velocities. Currently, this observation cannot be fully explained albeit squirt-flow type mechanisms on the microscale have been speculated to be the cause. Recent major findings from in situ experiments, using the "gas in excess" and "water in excess" formation method, and coupled with high-resolution synchrotron-based X-ray micro-tomography, have revealed the systematic presence of thin water films between the quartz grains and the encrusting hydrate. The data obtained from these experiments underwent an image processing procedure to quantify the thicknesses and geometries of the aforementioned interfacial water films. Overall, the water films vary from sub-micrometer to a few micrometers in thickness. In addition, some of the water films interconnect through water bridges. This geometrical analysis is used to propose a new conceptual squirt flow model for hydrate bearing sediments. A series of numerical simulations is performed considering variations of the proposed model to study seismic attenuation caused by such thin water films. Our results support previous speculation that squirt flow can explain high attenuation at seismic frequencies in hydrate bearing sediments, but based on a conceptual squirt flow model which is geometrically different than those previously considered.
\end{abstract}

\section{Introduction}

Important mechanisms of wave attenuation in fluid-saturated porous media from seismic to ultrasonic frequencies, include friction between grain boundaries (Winkler and Nur, 1982), global flow or Biot's mechanism (Biot, 1962), and waveinduced fluid flow at mesoscopic and microscopic scales (e.g., Müller et al., 2010). At the mesoscopic scale, patchy saturation and fractures are the most prominent causes of wave-induced fluid flow (White, 1975; White et al., 1975; Brajanovski et al., 2005; Tisato and Quintal, 2013; Quintal et al., 2014). At the microscopic scale, wave-induced fluid flow is commonly referred to as squirt flow and typically occurs between interconnected microcracks or between grain contacts and stiffer pores (O'Connell and Budiansky, 1977; Murphy et al., 1986; Mavko and Jizba, 1991; Sams et al., 1997; Adelinet et al., 2010; Gurevich et al., 2010). The attenuation caused by global flow as well as that caused by wave-induced fluid flow at microscopic or mesoscopic scales are frequency dependent. While the latter can have a strong effect at seismic frequencies (Pimienta et al., 2015; Subramaniyan et al., 2015; Chapman et al., 2016), global flow will only cause significant attenuation in reservoir rocks at ultrasonic frequencies or higher (e.g., Bourbie et al., 1987). The attenuation caused by friction between grain boundaries is, however, frequency independent and basically depends on the confining pressure and the strain imposed by the propagating wave (Winkler and Nur, 1982). Its effect is expected to be small for the correspondingly small strains caused by seismic waves used in exploration and reservoir geophysics. 
Furthermore, the attenuation caused by wave-induced fluid flow tends to be linearly superposed to that due to friction between grain boundaries, as shown by Tisato and Quintal (2014).

Gas hydrates (GH) are ice-like structures comprised of gas molecules entrapped by water molecules (Sloan and Koh, 2008). The widespread global occurrence of GH and the fact that $1 \mathrm{~m}^{3}$ of $\mathrm{GH}$ contains up to $164 \mathrm{~m}^{3}$ of natural gas $\left(\mathrm{CH}_{4}\right.$ and $\mathrm{CO}_{2}$ at standard conditions) draws attention to the idea of using GH as a potential future energy resource (Schicks et al., 2011). Nevertheless, GH-bearing sediments have been discussed not only as a relatively clean hydrocarbon reservoir (Collett and Ladd, 2000), but also as a geohazard that could potentially contribute to global warming associated with hydrate dissociation and the subsequent destabilization of GHcemented deep sea sediments at continental margins (Kvenvolden, 1993; Nixon and Grozic, 2007). Occurrences of GH are restricted to locations providing the required amount of gas and water and the preferred pressure-temperature $(p / T)$ conditions, which are commonly referred to as gas hydrate stability zones. Usually, GH reservoirs are mainly limited to marine continental margins, deep lakes and permafrost regions (Bohrmann and Torres, 2006).

In the search for GH reservoirs, the attenuation of seismic waves caused by the pore fluids might be an important survey tool (e.g., Bellefleur et al., 2007). However, little effort has been directed toward studying its effects for unconsolidated sediments hosting $\mathrm{GH}$ in a rather dispersed manner. GH forming in the pore space of unconsolidated sediments at given $p / T$ conditions alters the effective elastic and effective transport properties of the hosting sediment. It is known that the presence of GH in the sediment not only reduces the porosity and causes significant changes in its permeability, but also results in higher $\mathrm{P}$ and $\mathrm{S}$ wave velocities due to stiffening of the hosting matrix (Dvorkin et al., 2003; Guerin and Goldberg, 2005; Yun et al., 2005; Priest et al., 2006; Waite et al., 2009). In other words, the bulk and shear moduli increase due to the GH matrix-supporting effect within the sedimentary frame (Ecker et al., 1998). Additionally, the presence of GH causes higher attenuation of the seismic waves (Bellefleur et al., 2007; Dewangan et al., 2014) which was in particularly observed for sediments containing dispersed GH in the pore space (Guerin and Goldberg, 2002; Dvorkin and Uden, 2004). This anomalous seismic behavior in terms of increased attenuation and velocities (Guerin and Goldberg, 2002; Dvorkin and Uden, 2004) cannot be fully explained, although wave-induced fluid flow at the microscopic and mesoscopic scales has been speculated to cause them (Priest et al., 2006; Gerner et al., 2007). Gerner et al. (2007) conducted numerical $\mathrm{P}$ wave velocity simulations in highly permeable sedimentary layers, similar to hydrate-bearing sediments, and identified interlayer flow at the mesoscopic scale (White et al., 1975) as a potential mechanism of attenuation. Other authors have considered classical squirt flow models (O'Connell and Budiansky, 1977; Murphy et al., 1986) as

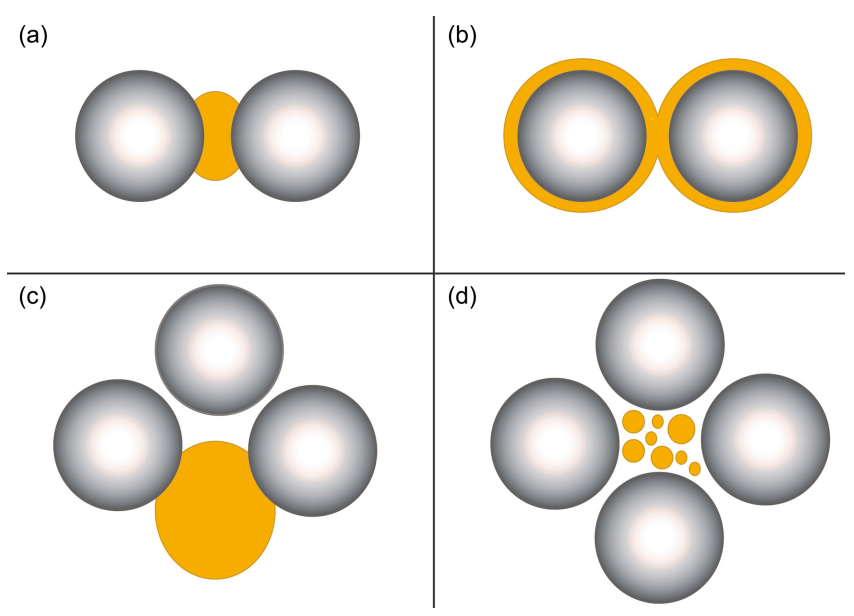

Figure 1. Review of the established conceptual models (grains are grey and GH are orange), with (a) cementation - GH cements the grains; (b) encrustation - GH coats the grains; (c) matrix-supporting - GH is part of the sediment matrix; and (d) pore-filling - GH employs the pore space forming crystallites of varying size (modified after Dai et al., 2004).

the main source of attenuation in hydrate-bearing sediments (Dvorkin and Uden, 2004; Guerin and Goldberg, 2005; Priest et al., 2006; Waite et al., 2009; Marin-Moreno et al., 2017).

Quantifying GH saturation levels through geophysical exploration techniques is, however, not straightforward as there are still open questions on GH formation, its microstructure, and its distribution in the natural settings. Additionally, the recovery of unaltered natural GH samples is hampered due to their fast decomposition under ambient conditions. Therefore, various researchers have attempted to mimic the natural environment of GH-bearing sedimentary matrices in laboratory experiments (Berge et al., 1999; Ecker et al., 2000; Dvorkin et al., 2003; Yun et al., 2005; Spangenberg and Kulenkampff, 2006; Priest et al., 2006, 2009; Best et al., 2010, 2013; Hu et al., 2010; Li et al., 2011; Zhang et al., 2011; Dai et al., 2012; Schicks et al., 2013). The results of this collective effort established a number of conceptual models for the role of GH embedded in its sedimentary matrix (Fig. 1). Nevertheless, these approximations are currently unsatisfactory. Although it has been suggested that all hydrate habits known from laboratory investigations involving synthetic samples also occur in nature (Spangenberg et al., 2015), none of those simplified models can yield accurate predictions of GH saturations from field electric resistivity or seismic data alone (Waite et al., 2009; Dai et al., 2012).

Chaouachi et al. (2015) performed in situ experiments based on different formation mechanisms, including the "water in excess" and the "gas in excess" methods, to form gas hydrates in various sedimentary matrices. The in situ experiments coupled with high-resolution synchrotron-based X-ray micro-tomography (SRXCT) yielded 3-D images of sub-micrometer spatial resolution. Using the "gas in excess" 
method, the water present in the samples weds the grain surfaces and transforms into $\mathrm{GH}$ at the required $p / T$ conditions. When hydrate is formed with the "water in excess method" the grains will also be water wet, but these very thin (submicron) hydrate films between the grains and the hydrate structure will only occur at very high GH saturations. The resulting 3-D micro-tomography data revealed the systematic presence of interfacial water films between the pore-filling $\mathrm{GH}$ and the grains, independent of which formation method was used ("gas in excess" or "water in excess"). The observed interfacial water films are occasionally interconnected via water bridges but water pockets are also embedded in the $\mathrm{GH}$.

For this study, the SRXCT data presented by Chaouachi et al. (2015) underwent an image processing workflow in order to quantify the thicknesses of the thin interfacial water films. Based on the obtained results, we introduce a conceptual model for GH-bearing sediments to numerically study squirt flow. Our numerical simulations allow for the dispersion of the $\mathrm{P}$ wave modulus and the frequency-dependent $\mathrm{P}$ wave attenuation. The results demonstrate the high levels of seismic attenuation/dispersion that a range of variations of our conceptual model can cause. Additionally, our results support the suggestions that the estimation of GH saturation for $\mathrm{GH}$ occurring in a rather dispersed manner could be accomplished by using seismic wave attenuation as a tool for indirect geophysical quantification (Guerin and Goldberg, 2002; Priest et al., 2006; Best et al., 2013; Marin-Moreno et al., 2017).

\section{The interfacial water films}

Chaouachi et al. (2015) conducted various in situ experiments coupled with synchrotron-based tomography at the TOMCAT beamline of the Paul Scherrer Institute in Villigen, Switzerland. The aim was to study the formation process and distribution of gas hydrates in various matrices, such as pure quartz sand and glass beads, as well as mixtures of quartz sand with clay minerals. These in situ experiments were conducted using an experimental setup that allowed for high pressures and low temperatures. Further details are given by Chaouachi et al. (2015), Falenty et al. (2015), and Sell et al. (2016).

For this study, the SRXCT data obtained from the abovementioned in situ experiments focused on samples containing pure natural quartz sand sieved at a $200-300 \mu \mathrm{m}$ grain size. Chuvilin et al. (2011) provides details on the sedimentology and mineralogy of the host sediment. We use a reconstruction process (Marone and Stampanoni, 2012) that yields an image matrix of $2560 \times 2560 \times 2160$ voxels, with isometric voxel sizes of 0.74 and $0.38 \mu \mathrm{m}$ at 10 fold and 20 fold optical magnification, respectively. The reconstructed tomograms revealed discernible grey value differences between the three relevant phases of the sample: solid grains, hydrate, and wa- ter (Fig. 2). To reduce image artifacts, such as inhomogeneity in grey scale values, streaks and edge enhancement, we apply a systematic image enhancement workflow comprising different image filter combinations in 2-D and 3-D (Sell et al., 2016). Chaouachi et al. (2015) observed the systematic appearance of an interfacial water film separating the quartz grains from the $\mathrm{GH}$ phase in samples where $\mathrm{GH}$ was formed directly from the juvenile state not involving GH dissociation, as well as where GH was formed from the "gas in excess method". This observation is in accordance with the publication from Tohidi et al. (2001). Additionally several molecular numerical simulations showed that water layers prefer the interface of GH and quartz grains (Bagherzadeh et al., 2012; Bai et al., 2011; Liang et al., 2011). Identifying the water films and quantifying their thickness was one scope of this study to adapt our conceptual model.

The broad range of grey scale values of the filtered images were classified using watershed segmentation combined with region growing tools from the Avizo Fire 7 (FEI, France) and Fiji software packages. In the present study, we determined the thickness variation and geometry of the water film (Fig. 3). Following the image enhancement and segmentation process described by Sell et al. (2016), the segmented data illustrate the characteristics and appearance of the phases distributed in the samples (Fig. 4). Moreover, the high resolution of the data enables us to obtain 3-D images in which particular details, such as water bridges connecting two interfacial water films, are detectable (Fig. 5). With information collected from the 3-D data, our proposed conceptual model involves spherical grains covered by a homogenous water film which is, in turn, embedded in non-porous hydrate. The conceptual model can be adjusted to include water bridges connecting the water films (Fig. 6) and/or isolated water pockets within the hydrate and separated from the water films.

\section{Numerical methodology}

\subsection{Mathematical formulation}

To estimate frequency-dependent attenuation in the GH systems described above we employ a hydromechanical approach (Quintal et al., 2016) based on the conservation of momentum.

$\nabla \cdot \sigma=0$,

with the components $\sigma_{k l}$ of the stress tensor $\sigma$ defined according to the general stress-strain relations in the frequency domain:

$\sigma_{k l}=2 \mu \varepsilon_{k l}+\left(K-\frac{2}{3} \mu\right) e \delta_{k l}+2 \eta \omega i \varepsilon_{k l}-\frac{2}{3} \eta \omega i e \delta_{k l}$,

where $\varepsilon_{k l}$ denotes the components of the strain tensor, $e$ denotes the cubical dilatation given by the trace of the strain tensor, $\omega$ is the angular frequency, and $i$ represents the unit 
(a)

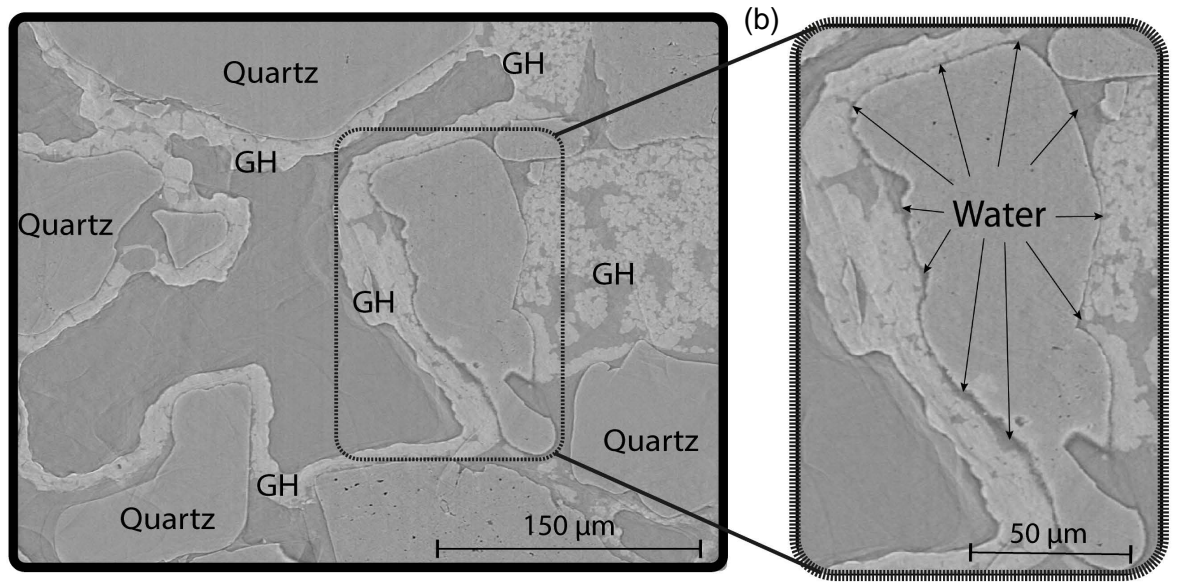

Figure 2. (a) Overview of an unfiltered 2-D slice in $y, z$ direction of quartz sand containing GH. Note that due to its unfiltered state this image contains artifacts, such as streaks and slight edge enhancement. Phases can be identified based on grey scale differences.

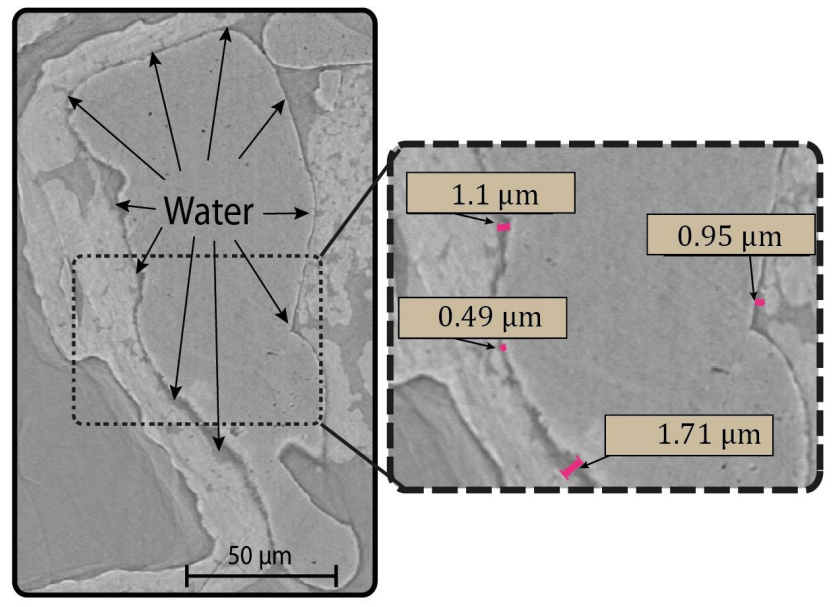

Figure 3. Raw (unfiltered) 2-D image in $y, z$ direction at a spatial resolution of $0.38 \mathrm{~m}$. The zoom depicts the measurement of a thin interfacial water film varying in thickness from 0.49 to $1.71 \mu \mathrm{m}$.

imaginary number. The indexes $k, l=1,2,3$ refer to the three Cartesian directions $x_{1}, x_{2}, x_{3}$ or $x, y, z$ and $\delta_{k l}$ is the Kronecker delta $\left(\delta_{k l}=1\right.$ for $k=l$ and $\delta_{k l}=0$ for $\left.k \neq l\right)$. The material parameters $\mu, K$, and $\eta$ are the shear modulus, the bulk modulus, and the shear viscosity, respectively.

Using this general mathematical formulation (Eqs. 1 and 2), a heterogeneous medium can be described as having an isotropic, linear elastic solid frame and fluid-filled cavities or pores, to which a specific choice of material parameters can be assigned. Equation (2) reduces to Hooke's law by setting the shear viscosity $\eta$ to zero in the solid domains. In these regions, $\mu$ and $K$ denote the shear and bulk moduli of the corresponding elastic solid. In the fluid-filled domains, the shear modulus $\mu$ is set to zero while $K$ and $\eta$ denote the bulk modulus and shear viscosity of the fluid. In these domains the combined Eqs. (1) and (2) reduce to the quasi- (a)

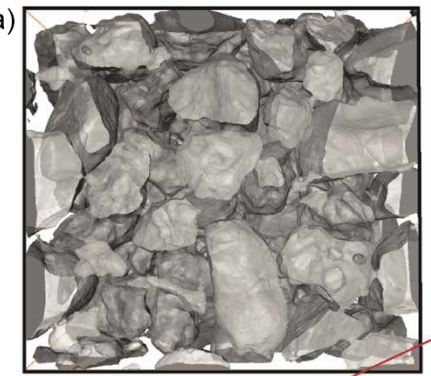

(b)

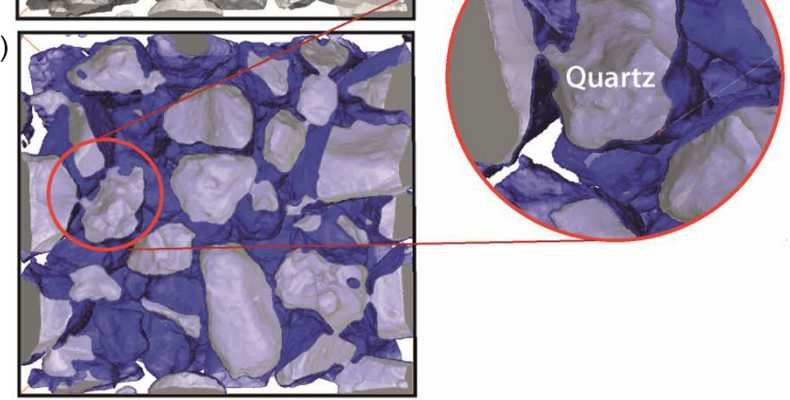

(c)

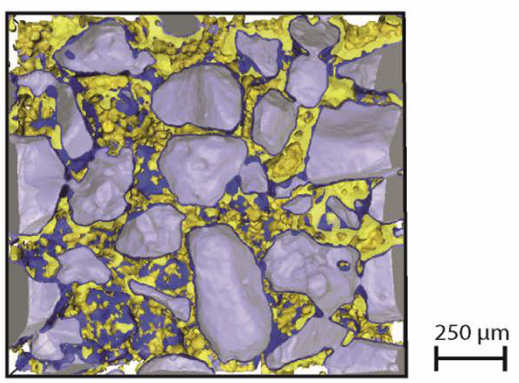

Figure 4. Volume-rendered phases in a representative image sample. For a better visualization the phases are introduced step-bystep, with (a) grains (grey), (b) grains and interfacial water films (blue), and (c) grains, water film and hydrate (yellow). A zoom in (b) shows an interfacial water film measured at 1-4 voxels equivalent to $0.38-1.52 \mu \mathrm{m}$ thickness, respectively. 


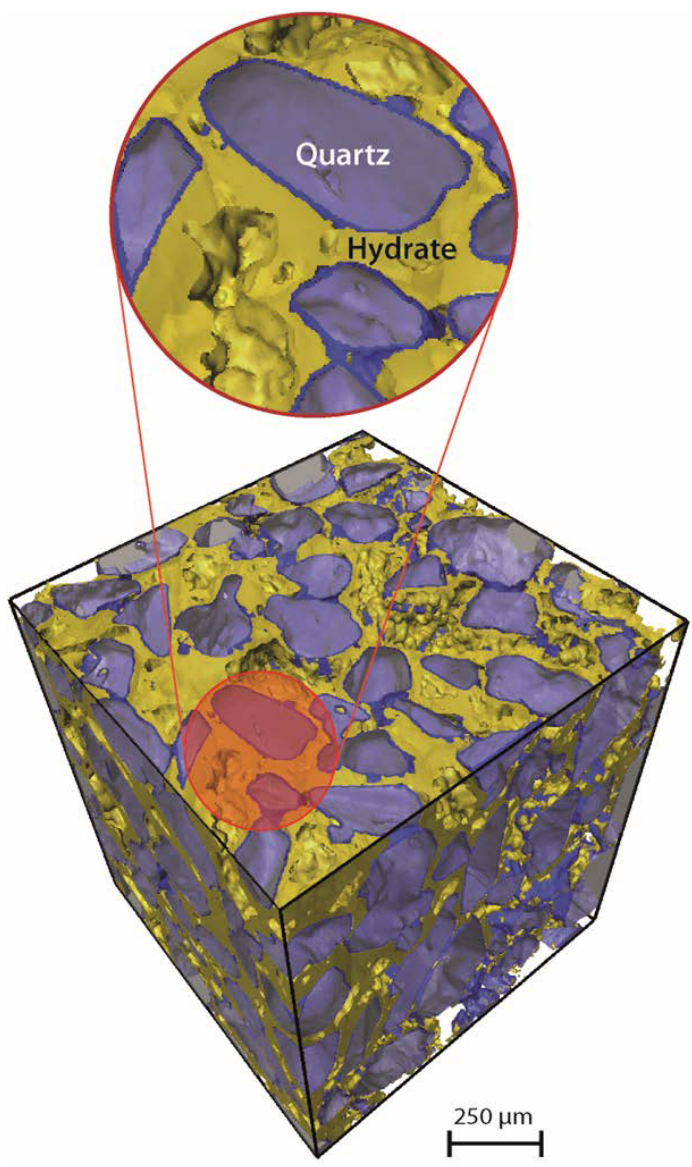

Figure 5. Volume-rendered image of a representative region of interest $(\mathrm{ROI})$ of $600 \times 600 \times 600$ voxels at $0.38 \mu \mathrm{m}$ spatial resolution. The zoom-in depicts quartz grains fully separated from the porefilling hydrate by thin interfacial water films, with two quartz grains having their water films interconnected by a water bridge.

static, linearized Navier-Stokes' equations for the laminar flow of a Newtonian fluid (e.g., Jaeger et al., 2007).

When the aforementioned heterogeneous medium is deformed, fluid pressure differences between neighbor regions induce fluid flow or, more accurately, fluid pressure diffusion, which in turn results in energy loss caused by viscous dissipation (Quintal et al., 2016). At the microscopic scale, this attenuation mechanism is commonly referred to as squirt flow (e.g., O'Connell and Budiansky, 1977; Murphy et al., 1986) and is the sole cause of attenuation in our simulations, as we neglect the inertial terms in Eqs. (1) and (2).

\subsection{Finite element modeling}

Our 2-D problem is equivalent to a 3-D case under plain strain conditions, which means no strain outside the modeling plane is allowed to develop. For the corresponding simulations, we consider the directions $x$ and $y$, to be in the modeling plane and direction $z$ to be the direction in which no displacement or displacement gradients can occur.
The numerical solution is based on a finite-element approach in the frequency domain. We employ an unstructured triangular mesh which allows for an efficient discretization of slender heterogeneities having large aspect ratios, such as the thin interfacial water films, by strongly varying the sizes of the triangular elements (e.g., Quintal et al., 2014). A few elements across the thin interfacial water film are necessary to accurately capture the viscous dissipation in this region, while much larger elements are sufficient in the solid elastic domains. The sizes of smallest and largest elements in our meshes differ by three orders of magnitude.

To assess the $\mathrm{P}$ wave attenuation and modulus dispersion caused by squirt flow, we subject a rectangular numerical model to an oscillatory test. A sinusoidal downward displacement is applied homogeneously at the top boundary of the numerical model. At the bottom, the displacement in the $(y)$ vertical direction is set to zero. At the lateral boundaries of the model, the displacement in the $(x)$ horizontal direction is set to zero. From this test we obtain the stress and strain fields, averaged over the entire model domain. The mean stress and strain are used to compute the complex-valued and frequency-dependent $\mathrm{P}$ wave modulus corresponding to a wave propagating in the vertical direction. The real part of the $\mathrm{P}$ wave modulus $(H)$ is used to illustrate the $\mathrm{P}$ wave modulus dispersion while the ratio between its imaginary and real parts is used to quantify the $\mathrm{P}$ wave attenuation $\left(1 / Q_{P}\right)$. The $S$ wave attenuation and dispersion can be evaluated in a similar manner by changing the boundary conditions to those of a simple shear test (e.g., Quintal et al., 2012, 2014).

Similar to the 2-D problem, the solution to our 3-D problem is based on the application of an unstructured mesh with tetrahedral elements. The element sizes in our 3-D meshes also vary by about three orders of magnitude.

\section{Numerical results}

Many sources of squirt flow might coexist in unconsolidated sediments hosting GH, such as those resembling the conventional squirt flow models introduced by O'Connell and Budiansky (1977) for interconnected microcracks and by Murphy et al. (1986) for microcracks or grain contacts connected to spherical pores. Marin-Moreno et al. (2017) describes an integrated approach that combines the effects of some squirt flow models and other attenuation mechanisms. Here our objective diverges from that. We instead aim at studying the squirt flow phenomenon and the resulting frequency-dependent attenuation associated with a specific model, which is geometrically different from the previously mentioned conventional squirt flow models and is based on the thin interfacial water films. We thus neglect all other potential sources of attenuation. 
(a)

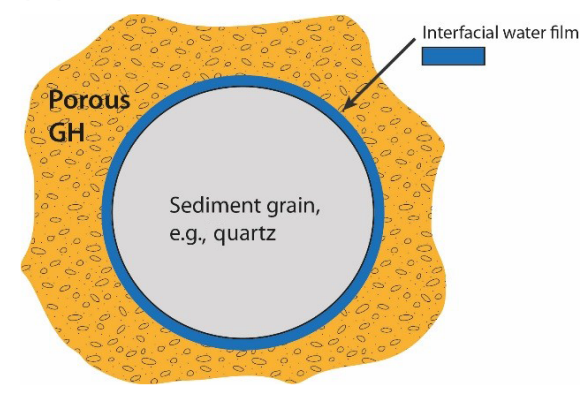

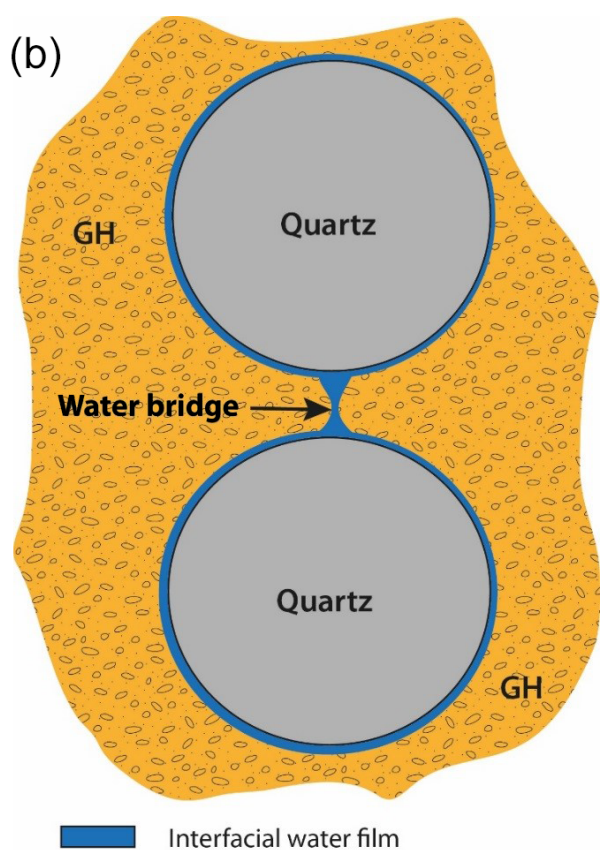

Figure 6. Schemes of (a) a new concept model for GH encrusting quartz grains separated by a thin interfacial water film and (b) connected by a water bridge.

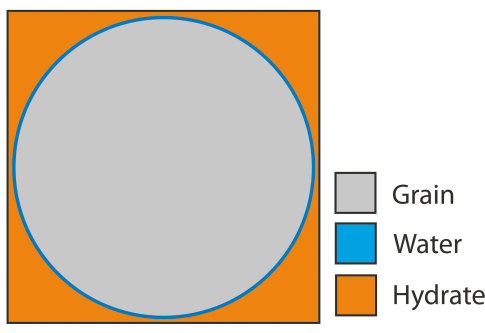

Figure 7. Fundamental block of an idealized periodic medium representing sediment grains which are separated from the embedding $\mathrm{GH}$ background by a thin interfacial water film.

Table 1. Material properties used in the numerical simulations. The properties of quartz are based on the work of Bass (1995) and those of hydrate on Helgerud (2003).

\begin{tabular}{llll}
\hline Material parameter & Quartz & Hydrate & Water \\
\hline Shear modulus $(\mu)$ & $44.3 \mathrm{GPa}$ & $13.57 \mathrm{GPa}$ & 0 \\
Bulk modulus $(K)$ & $37.8 \mathrm{GPa}$ & $8.76 \mathrm{GPa}$ & $2.4 \mathrm{GPa}$ \\
Shear viscosity $(\eta)$ & 0 & 0 & $0.003 \mathrm{~Pa}$ \\
\hline
\end{tabular}

\subsection{Attenuation mechanism in a thin interfacial water film}

Our 2-D numerical model domain corresponds to a fundamental block of a periodic distribution of unconsolidated circular quartz grains dispersed in a continuous GH background and separated from the latter by a thin interfacial water film
(Fig. 7). The subdomain representing the thin interfacial water film is described by the corresponding properties of this viscous fluid, while the other subdomains are described by properties of two different elastic solids (quartz and GH). These properties are given in Table 1 and the numerical mesh is shown in Fig. 8. We consider thicknesses of the interfacial water film ranging from 0.1 to $1 \mu \mathrm{m}$ as well as two grain diameters 150 and $250 \mu \mathrm{m}$ for the 2-D model. These values were chosen considering the sizes of the quartz grains used in the laboratory experiment from which the SRXCT data were obtained, which ranged from 150 to $300 \mu \mathrm{m}$, and the thicknesses of the interfacial water films observed in the data, ranging from 0.38 to $1.5 \mu \mathrm{m}$. Note that the thinnest interfacial water films observed were limited by the highest achieved spatial resolution of $0.38 \mu \mathrm{m}$. Despite this limitation, water film thicknesses below $0.38 \mu \mathrm{m}$ have also been considered for our numerical analysis.

The numerical results are expressed as the real part of the $\mathrm{P}$ wave modulus and the $\mathrm{P}$ wave attenuation $\left(1 / Q_{P}\right)$ (Fig. 9). We observe that a decrease in the thickness of the interfacial water film causes the attenuation and dispersion curves to shift to lower frequencies. In fact, high attenuation values $(1 / Q \sim 0.1)$ are observed at seismic frequencies $(\sim 100 \mathrm{~Hz})$ when the interfacial water film is as thin as $0.1 \mu \mathrm{m}$ and the grain diameter is as large as $250 \mu \mathrm{m}$. Decreasing the grain diameter causes a shift of the attenuation and dispersion curves to higher frequencies.

The geometry of the introduced model (Fig. 7) is different to the classical squirt-flow geometries involving interconnected plane cracks or a plane crack connected to a low as- 

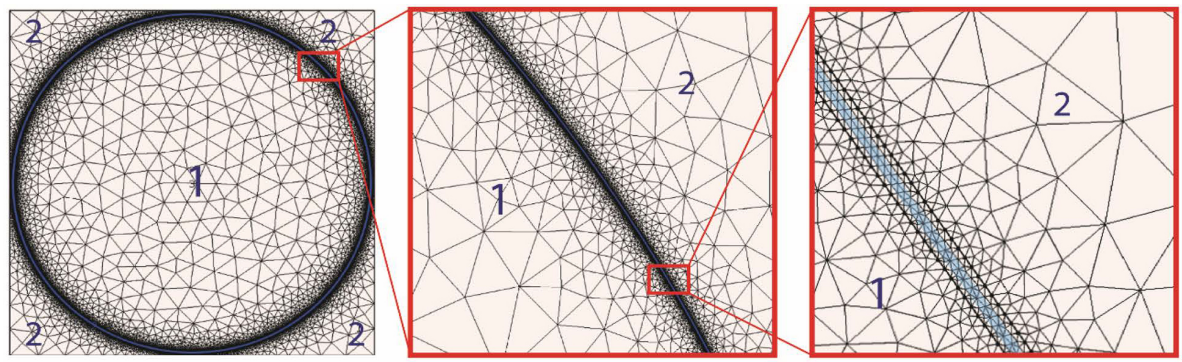

Figure 8. The triangular mesh used for the numerical model shown in Fig. 7. To distinguish between the phases: quartz is denoted with \#1, $\mathrm{GH}$ is denoted with \#2, and the interfacial water film is depicted in light blue.

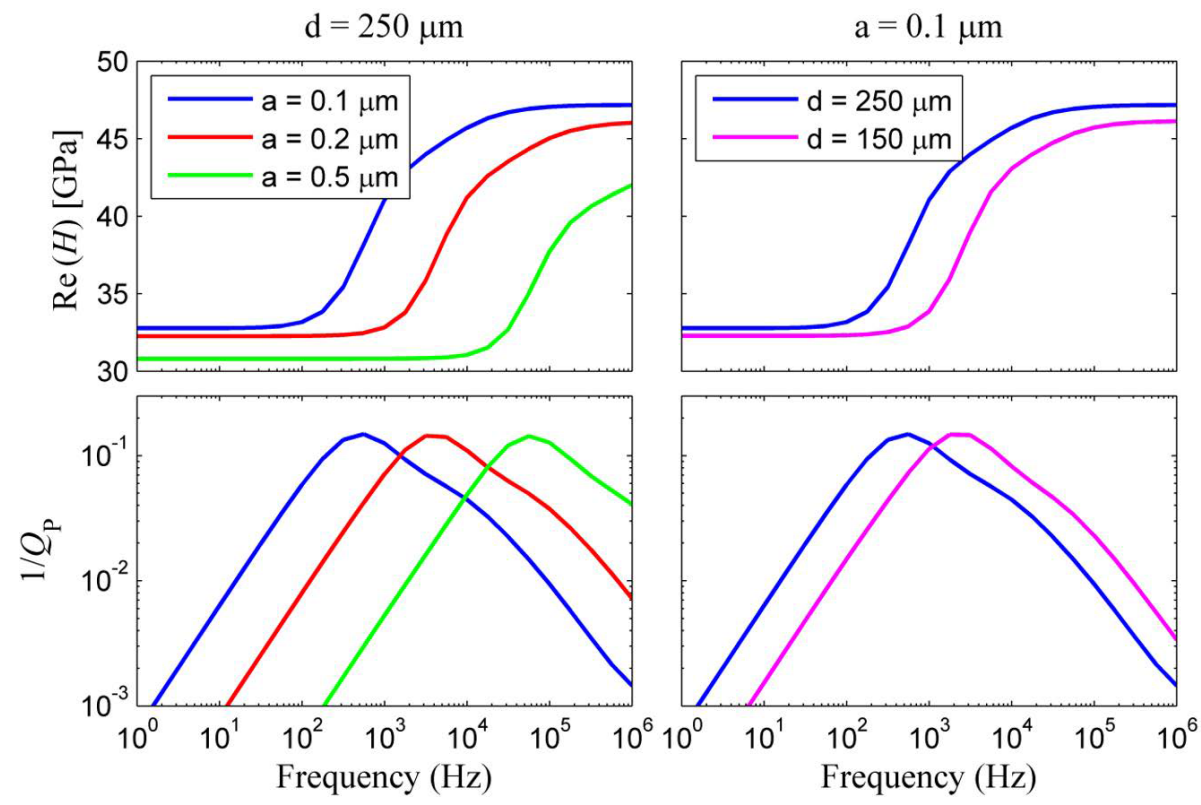

Figure 9. Real part of $\mathrm{P}$ wave modulus, $H$, and corresponding $\mathrm{P}$ wave attenuation, $1 / Q_{P}$, as functions of frequency for the model shown in Fig. 7, considering the grain diameter $(d)$ and thickness $(a)$ of the interfacial water film, which are indicated in the legends and plot titles.

pect ratio pore. To better understand how dissipation occurs for this type of geometry, we initially focus on the fluid pressure field $P$ (Fig. 10) in the circular interfacial water film at the characteristic frequency. The vertical compression of the model illustrated in Fig. 7 causes a larger deformation of the interfacial water film at the top and bottom than on the lateral sections. This observation is comparable to horizontal cracks that are more deformed by vertical compression than vertical cracks in a classical squirt flow model. Here, the heterogeneous deformation causes fluid pressure to increase. The most deformed parts which are the top and the bottom, exhibit the highest fluid pressure, as shown in Fig. 10. The pressure gradient present in this heterogeneous pressure field induces fluid to be displaced from the regions of higher pressure (top and bottom) towards the regions of lower pressure (left and right). The components of the fluid velocity field in the $x$ and $y$ directions, $V_{x}$ and $V_{y}$ (Fig. 11), and the corresponding local attenuation field, $1 / q$ (Fig. 12), are only de- picted in the top right quadrant of the model. Considering the symmetry of this process in the four quadrants of the circular interfacial water film (Fig. 10) it is sufficient to show only one quadrant.

In Fig. 11 we observe the text book (e.g., Jaeger et al., 2007) parabolic profile of the fluid velocity across the interfacial water film, with larger fluid velocity in the center of the film, governed by Navier-Stokes equations. This fluid velocity is associated with an energy dissipation caused by viscous friction, shown in Fig. 12. At the boundaries of the interfacial water film, larger viscous friction explains the lower fluid velocity and larger energy dissipation, in comparison to the center of the film. The attenuation is strongly reduced towards the center of the film by a few orders of magnitude. Looking at how these fields change along the interfacial water film, we observe that the maximal velocity and attenuation (compare Figs. 11 and 12) coincide with the maximal pressure gradient (Fig. 10). In contrast, in the middle of the 


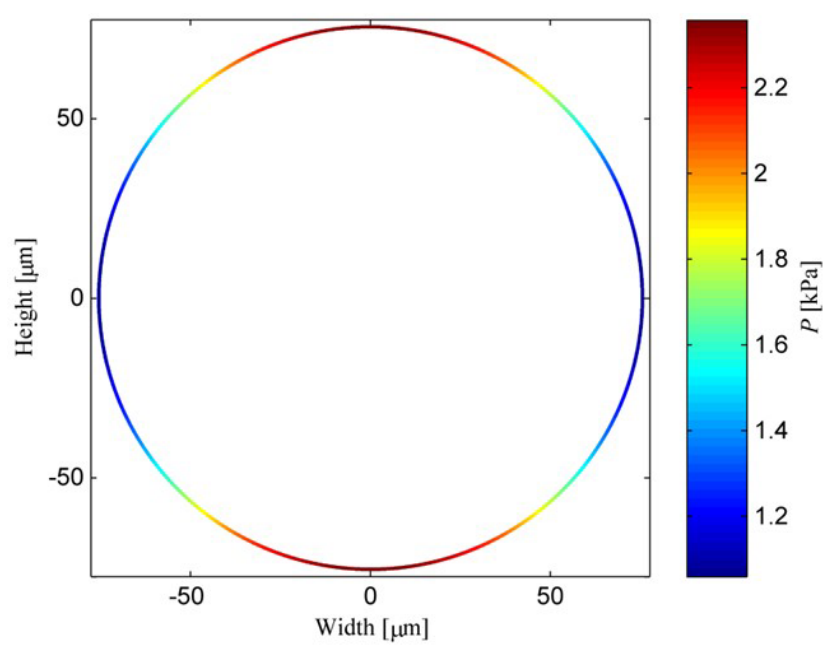

Figure 10. Fluid pressure $P$ for the model shown in Fig. 7, considering a grain diameter $d=150 \mu \mathrm{m}$ and thickness of the interfacial water film $a=1 \mu \mathrm{m}$. The oscillation frequency is equal to the characteristic frequency $\left(1.8 \times 10^{6} \mathrm{~Hz}\right)$.

higher pressure and lower pressure regions, the pressure gradient is minimal causing the fluid velocity and attenuation to drop drastically.

\subsection{Effects of water pockets and water bridges}

In this subsection, a few alterations are added to the basic model illustrated in Fig. 7. These alterations are based on more detailed observations obtained from SRXCT, such as water pockets in non-porous $\mathrm{GH}$ or a water bridge which might occur and connect two neighboring interfacial water films (Fig. 13). The effect of these abovementioned features on the $\mathrm{P}$ wave modulus dispersion and attenuation (Fig. 14) is studied and compared to results obtained from corresponding models where these features have not been considered.

The inclusion of water pockets has a modest effect on the attenuation and dispersion, while it reduces the overall value of the $\mathrm{P}$ wave modulus, as a certain volume of $\mathrm{GH}$ is replaced by a much less stiff material (water). The modest increase in attenuation is associated with a more compressible effective background; no attenuation occurs within the water pockets.

The connecting water bridge introduces an additional length scale for the dissipation process, as fluid flow and dissipation will also occur through this relatively short and wide path. This explains the additional attenuation peak observed at higher frequencies, while the previous peak at $2 \times 10^{3} \mathrm{~Hz}$ suffers a slight reduction in magnitude. A reduction in magnitude occurs because the pressure equilibration process involving the water bridge causes a reduction in pressure in the region connected to the bridge and thus a reduction of the previously discussed (Fig. 9) pressure gradient between this region and the sides of the circular interfacial water film. The dispersion agrees with the attenuation curve, with two inflec- tions corresponding to the two attenuation peaks between the high- and low-frequency limits.

\subsection{Evaluation of 3-D effects}

This subsection considers a comparison between the results of the simulation illustrated in Figs. 10-12, for the 2-D model shown in Fig. 7, and those of a simulation performed on its 3-D counterpart. Our 3-D model consists of a sphere in the middle of a cube (Fig. 15), for which a centered cross section matches the 2-D model shown in Fig. 7. The thickness of the water film is $1 \mu \mathrm{m}$ and the grain diameter is $150 \mu \mathrm{m}$ (as for Figs. 10-12). The numerical results are shown in Fig. 16 with an excellent agreement between the results from the 2-D and 3-D models in terms of magnitude and the characteristic frequency of attenuation. Indeed this was expected due to the radial symmetry of the spherical interfacial water film. This outcome indicates that 3-D effects are small for the adopted geometry. The results based on simple 2-D models approximate the dissipation magnitude and frequency dependence of their corresponding 3-D scenarios well. The difference in the overall value of the real-valued $\mathrm{P}$ wave modulus is associated with a larger relative quantity of soft $\mathrm{GH}$ and a lower relative quantity of stiff quartz in the 3-D model.

\section{Conclusions}

Interfacial water films between sediment grains and the embedding GH matrix were recently observed in GH-bearing sediments through synchrotron-based micro-tomography at a spatial resolution down to $0.38 \mu \mathrm{m}$. Based on these data, we have determined the appearance and thicknesses of such films. With this knowledge, a new conceptual squirt flow model, which refers to a spherical water film coating the solid grains, was introduced for GH-bearing sediments. This geometry differs from the classical squirt flow models involving microcracks, interconnected or connected to spherical pores. Numerical simulations were performed to calculate the energy dissipation in the proposed model, considering a range of scenarios. Our results show that squirt flow in spherical interfacial water films can cause large and frequency-dependent $\mathrm{P}$ wave attenuation in a broad frequency range including seismic frequencies.

The numerical scheme is based on a set of coupled equations that reduce to Hooke's law in the subdomains of the model corresponding to the elastic solid materials (grains and $\mathrm{GH}$ ) and to the quasi-static, linearized Navier-Stokes equations in the subdomains corresponding to the fluid (water). The results for our conceptual model show that the $\mathrm{P}$ wave attenuation peak is shifted to lower frequencies with decreasing thickness of the interfacial water film and with increasing grain size (or the length of the film), as analogously known for the microcrack aperture and length in classical squirt flow models. Furthermore, we tested the effect of inserting wa- 

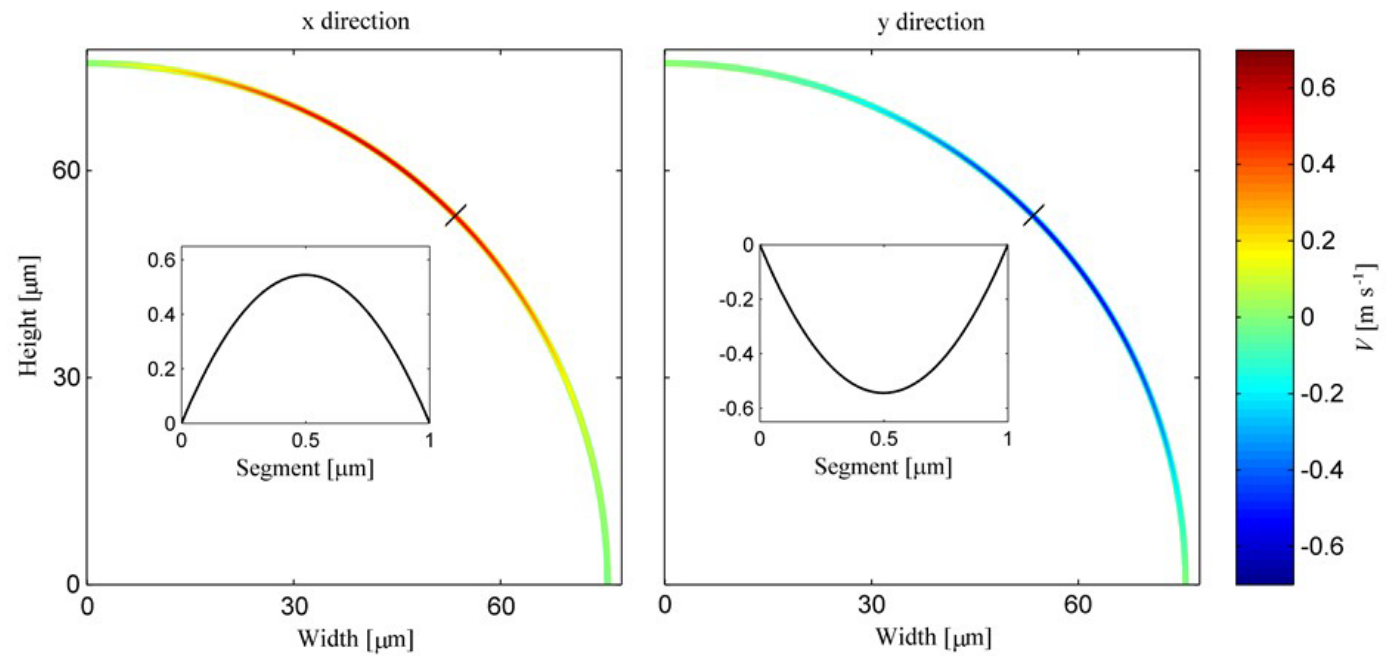

Figure 11. Zoom-in of the top right quadrant of the model shown in Fig. 9 displaying the fluid velocity components ( $V_{x}$ and $V_{z}$ ) for a grain diameter $d=150 \mu \mathrm{m}$ and a thickness of the interfacial water film $a=1 \mu \mathrm{m}$, at the characteristic frequency. These fields correspond to the fluid pressure field shown in Fig. 10. The insets illustrate the profiles across the interfacial film where it is crossed by a black line.

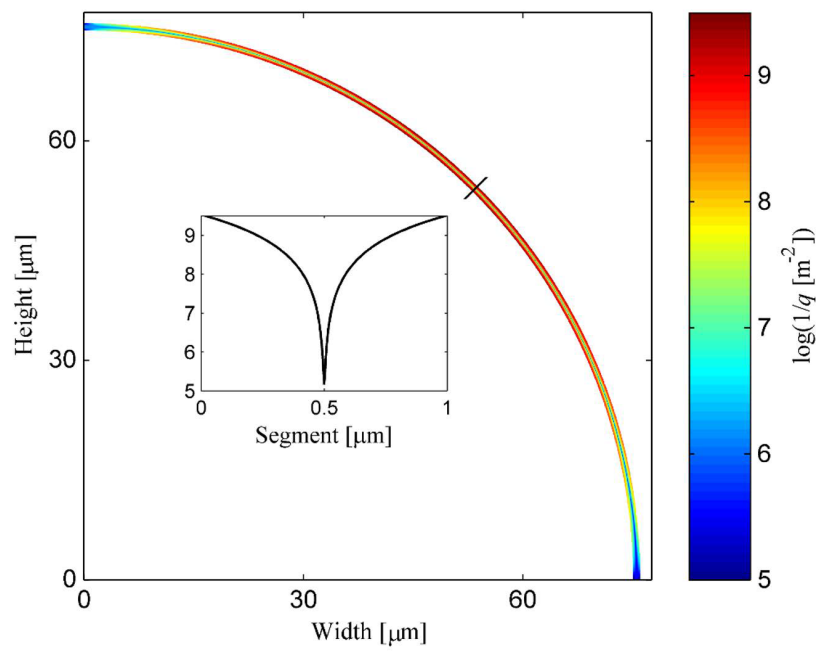

Figure 12. Zoom-in of the top right quadrant of the model shown in Fig. 7 showing the local attenuation $(1 / q)$ for a grain diameter $d=$ $150 \mu \mathrm{m}$ and a water film thickness $a=1 \mu \mathrm{m}$, at the characteristic frequency. This field corresponds to those shown in Figs. 10 and 11. The inset illustrates the profile across the interfacial film where it is crossed by a black line.

ter pockets in an embedding GH matrix and the effect of connecting two neighboring interfacial water films through a water bridge. In general, the water bridges have a stronger effect on energy dissipation than the water pockets. Introducing such connections between neighboring interfacial water films causes a broadening of the $P$ wave attenuation spectrum towards higher frequencies. Conversely, the presence of water pockets in the GH background only causes a slight overall increase in $\mathrm{P}$ wave attenuation. Although the majority of our

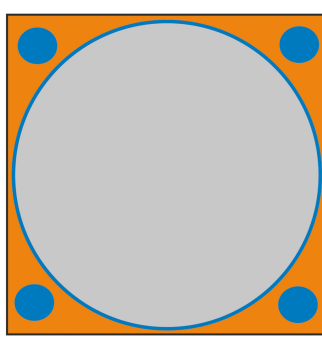

(a)

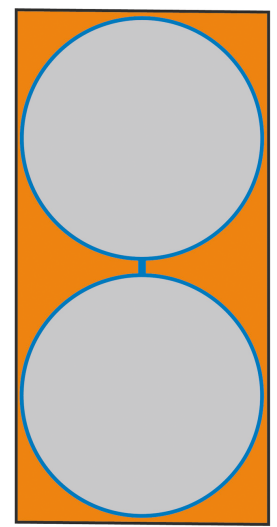

(b)

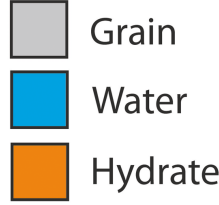

Figure 13. Fundamental blocks of two periodic media representing loose sandstone grains which are separated from the embedding $\mathrm{GH}$ background by a thin interfacial water film. In (a) water pockets are located in the GH background and in (b) the interfacial water films are connected to another through a water bridge.

simulations were performed for 2-D models, results of a 3D simulation showed that 3-D effects are small for the basic 2-D models that we have considered.

Our results represent a strong base to explain fundamental processes in GH-bearing sediments and support previous speculations (Guerin and Goldberg, 2002; Dvorkin and Uden, 2004; Priest et al., 2006) that squirt flow is an important attenuation mechanism in such media, even at frequencies as low as those in the seismic range. This strengthens the perception that $\mathrm{P}$ wave attenuation may be used as an indirect geophysical attribute to estimate GH saturation. Nevertheless, further studies considering more realistic geometries for 

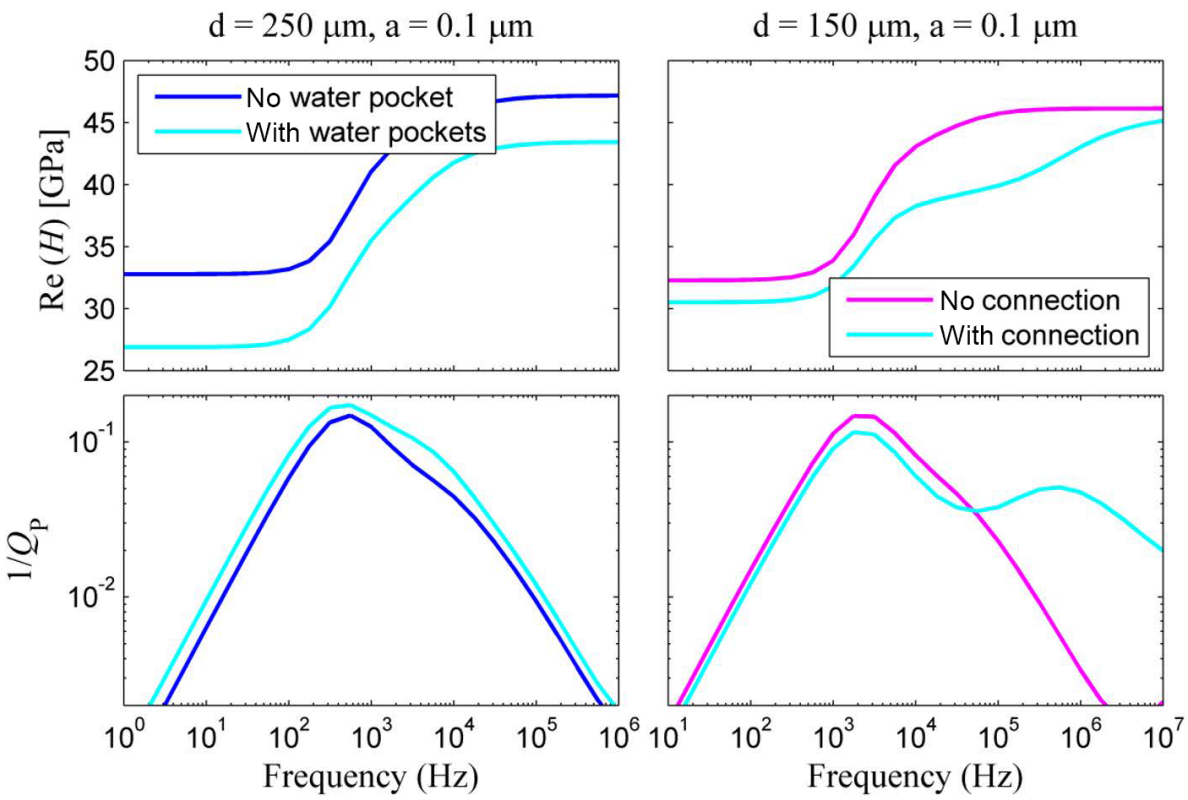

Figure 14. Real part of $\mathrm{P}$ wave modulus, $H$, and corresponding $\mathrm{P}$ wave attenuation, $1 / Q_{P}$, as functions of frequency, for the models shown in Fig. 13 in comparison with the corresponding results from the model shown in Fig. 7 and given in Fig. 9. The grain diameter $(d)$ and thickness $(a)$ of the interfacial water film are indicated in the plot titles.

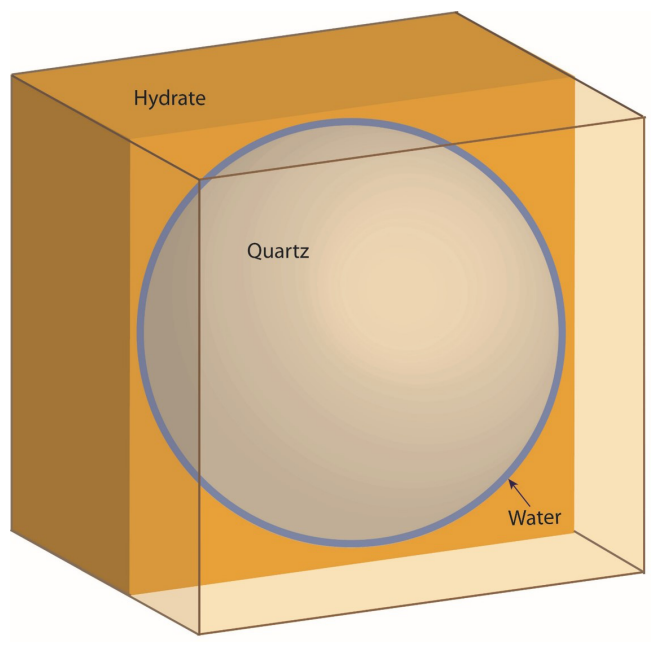

Figure 15. The 3-D counterpart of the model shown in Fig. 7: a fundamental block of a periodic medium representing unconsolidated quartz grains which are separated from the embedding GH background by a thin interfacial water film.

the microstructure of GH bearing sediments are necessary for the development of a successful strategy to estimate GH saturations, where hydrate is distributed in a dispersed manner instead of massive layers. This study represents the first attempt at understanding $\mathrm{P}$ wave attenuation in unconsolidated sediments which have large GH saturations. Following work will be aimed at implementing the segmented 3-D images obtained from synchrotron-based micro-tomography as a direct

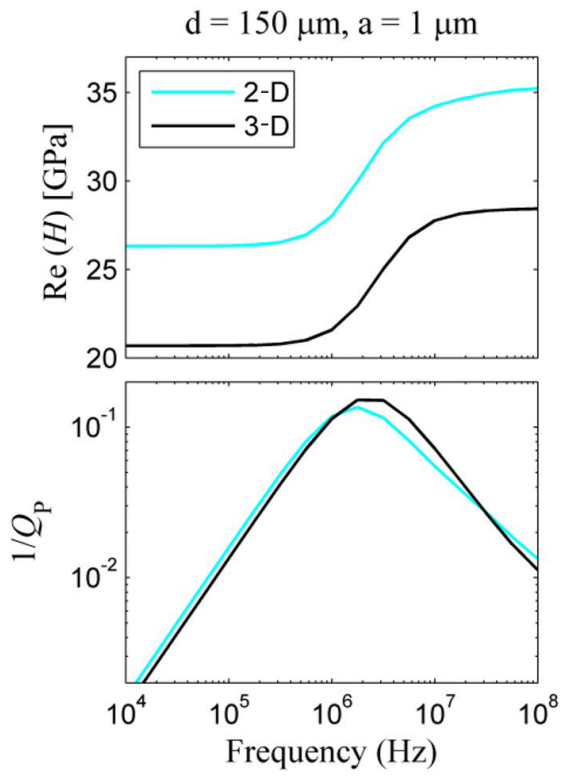

Figure 16. Real part of $\mathrm{P}$ wave modulus $(H)$ and corresponding $\mathrm{P}$ wave attenuation $\left(1 / Q_{P}\right)$, as functions of frequency, for the 2-D model shown in Fig. 7 and for its 3-D counterpart shown in Fig. 15. The grain diameter $(d)$ and thickness $(a)$ of the interfacial water film are indicated in the plot title. The fields shown in Figs. 10-12 correspond to this 2-D simulation.

model input for numerical investigations, whereby realistic grain-to-grain contacts will be taken into account. The step towards more realistic structures as a model input is challeng- 
ing due to the corresponding large computational demand. Furthermore, such model input requires additional segmentation steps for the 3-D images that allow for a smoothing of the stair-like resolution artifacts at the boundaries of the interfacial water films.

Data availability. The data can be accessed upon request from any of the authors.

Competing interests. The authors declare that they have no conflict of interest.

Acknowledgements. The authors thank the staff of the GZG crystallography group headed by Werner F. Kuhs of the Georg August University, Göttingen, for their collaboration during the in situ experiments at the TOMCAT beamline (Paul Scherrer Institute in Villigen, Switzerland) in 2012 and 2013. The presented work was co-funded by the German Science Foundation (DFG grant Ke 508/20 and $\mathrm{Ku}$ 920/18).

Edited by: Charlotte Krawczyk

Reviewed by: two anonymous referees

\section{References}

Adelinet, M., Fortin, J., Guéguen, Y., Schubnel, A., and Geoffroy, L.: Frequency and fluid effects on elastic properties of basalt: Experimental investigations, Geophys. Res. Lett., 37, L02303, https://doi.org/10.1029/2009GL041660, 2010.

Bagherzadeh, S. A., Englezos, P., Alavi, S., and Ripmeester, J. A.: Molecular modeling of the dissociation of methane hydrate in contact with a silica surface, J. Phys. Chem. B, 116, 3188-3197, https://doi.org/10.1021/jp2086544, 2012.

Bai, D., Chen, G., Zhang, X., and Wang, W.: Microsecond molecular dynamics simulations of the kinetic pathways of gas hydrate formation from solid surfaces, Langmuir, 27, 5961-5967, https://doi.org/10.1021/la105088b, 2011.

Bass, J. D.: Elasticity of Minerals, Glasses and Melts, in: Mineral physics and crystallography: a handbook of physical constants, edited by: Ahrens, T. J., American Geophysical Union, Washington DC, USA, 45-63, 1995.

Bellefleur, G., Riedel, M., Brent, T., Wright, F., and Dallimore, S. R.: Implication of seismic attenuation for gas hydrate resource characterization, Mallik, Mackenzie Delta, Canada, J. Geophys. Res., 112, B10311, https://doi.org/10.1029/2007JB004976, 2007.

Berge, L. I., Jacobsen, K. A., and Solstad, A.: Measured acoustic wave velocities of $\mathrm{R} 11\left(\mathrm{CCl}_{3} \mathrm{~F}\right)$ hydrate samples with and without sand as a function of hydrate concentration, J. Geophys. Res.Sol. Ea., 104, 15415-15424, 1999.

Best, A., Priest, J., and Clayton, C.: A Resonant Column Study of the Seismic Properties of Methane-Hydrate-Bearing Sand, in: Geophysical Characterization of Gas Hydrates, edited by:
Riedel, M., Willoughby, E. C., and Chopra, S., Society of Exploration Geophysicists, Tulsa, OK, USA, 337-347, 2010.

Best, A. I., Priest, J. A., Clayton, C. R. I., and Rees, E. V. L.: The effect of methane hydrate morphology and water saturation on seismic wave attenuation in sand under shallow sub-seafloor conditions, Earth Planet. Sci. Lett., 368, 78-87, 2013.

Biot, M. A.: Mechanics of deformation and acoustic propagation in porous media, J. Appl. Phys., 33, 1482-1498, https://doi.org/10.1063/1.1728759, 1962.

Bohrmann, G. T. M. E.: Gas Hydrates in Marine Sediments, in: Marine Geochemistry, Springer, Berlin Heidelberg, 481-512, 2006.

Bourbié, T., Coussy, O., and Zinszner, B.: Acoustics of porous media, Editions Technip, Paris, 1987.

Brajanovski, M., Gurevich, B., and Schoenberg, M.: A model for $P$ wave attenuation and dispersion in a porous medium permeated by aligned fractures, Geophys. J. Int., 163, 372-384, https://doi.org/10.1111/j.1365-246X.2005.02722.x, 2005.

Chaouachi, M., Falenty, A., Sell, K., Enzmann, F., Kersten, M., Haberthür, D., and Kuhs, W. F.: Microstructural evolution of gas hydrates in sedimentary matrices observed with synchrotron $\mathrm{X}$-ray computed tomographic microscopy, Geochem. Geophy. Geosy., 16, 1711-1722, 2015.

Chapman, S., Tisato, N., Quintal, B., Holliger, K.: Seismic attenuation in partially saturated Berea sandstone submitted to a range of confining pressures, J. Geophys. Res.-Sol. Ea., 121, 1664-1676, https://doi.org/10.1002/2015JB012575, 2016.

Chuvilin, E. M., Istomin, V. A., and Safonov, S. S.: Residual nonclathrated water in sediments in equilibrium with gas hydrate Comparison with unfrozen water, Cold Reg. Sci. Technol., 68, 68-73, 2011

Collett, T. S. and John, L.: 19. Detection of gas hydrate with downhole logs and assessment of gas hydrate concentrations (saturations) and gas volumes on the Blake Ridge with electrically resistivity log data, Proceedings of the Ocean Drilling Program, Scientific Results, Texas A\&M University, College Station, TX, USA, 164, 2000.

Dai, J., Xu, H., Snyder, F., and Dutta, N.: Detection and estimation of gas hydrates using rock physics and seismic inversion: Examples from the northern deepwater Gulf of Mexico, The Leading Edge, 23, 60-66, 2004.

Dai, S., Santamarina, J. C., Waite, W. F., and Kneafsey, T. J.: Hydrate morphology: Physical properties of sands with patchy hydrate saturation, J. Geophys. Res.-Sol. Ea., 117, B11205, https://doi.org/10.1029/2012jb009667, 2012.

Dewangan, P., Mandal, R., Jaiswal, P., Ramprasad, T., and Sriram, G.: Estimation of seismic attenuation of gas hydrate bearing sediments from multi-channel seismic data: A case study from Krishna-Godavari offshore basin, Mar. Petrol. Geol., 58, 356367, 2014.

Dvorkin, J. and Uden, R.: Seismic wave attenuation in a methane hydrate reservoir, The Leading Edge, 23, 730-732, 2004.

Dvorkin, J., Nur, A., Uden, R., and Taner, T.: Rock physics of a gas hydrate reservoir, The Leading Edge, 22, 842-847, 2003.

Ecker, C., Dvorkin, J., and Nur, A. M.: Sediments with gas hydrates: Internal structure from seismic AVO, Geophysics, 63, 1659-1669, 1998.

Ecker, C., Dvorkin, J., and Nur, A. M.: Estimating the amount of gas hydrate and free gas from marine seismic data, Geophysics, 65, 565-573, 2000. 
Falenty, A., Chaouachi, M., Neher, S. H., Sell, K., Schwarz, J.O., Wolf, M., Enzmann, F., Kersten, M., Haberthur, D., and Kuhs, W. F.: Stop-and-go in situ tomography of dynamic processes - gas hydrate formation in sedimentary matrices, Acta Crystallogr. A, 71, p. 154, https://doi.org/10.1107/S2053273315097740, 2015.

Gerner, A., Saenger, E. H., and Shapiro, S. A.: Attenuation of $P$ waves due to interlayer fluid flow in hydrate-bearing sediments, J. Geophys. Eng., 4, 394-403, 2007.

Guerin, G. and Goldberg, D.: Sonic waveform attenuation in gas hydrate-bearing sediments from the Mallik 2L-38 research well, Mackenzie Delta, Canada, J. Geophys. Res., 107, EPM 1-1-EPM 1-11, https://doi.org/10.1029/2001JB000556, 2002.

Guerin, G. and Goldberg, D.: Modeling of acoustic wave dissipation in gas hydrate-bearing sediments, Geochem. Geophys. Geosyst., 6, Q07010, https://doi.org/10.1029/2005GC000918, 2005.

Gurevich, B., Makarynska, D., de Paula, O. B., and Pervukhina, M.: A simple model for squirt-flow dispersion and attenuation in fluid-saturated granular rocks, Geophysics, 75, N109-N120, https://doi.org/10.1190/1.3509782, 2010.

Helgerud, M. B., Waite, W. F., Kirby, S. H., and Nur, A.: Measured temperature and pressure dependence of $\mathrm{vp}$ and vs in compacted, polycrystalline si methane and sii methane-ethane hydrate., Can. J. Phys., 81, 47-53, 2003.

Hu, G. W., Ye, Y. G., Zhang, J., Liu, C. L., Diao, S. B., and Wang, J. S.: Acoustic properties of gas hydrate-bearing consolidated sediments and experimental testing of elastic velocity models, J. Geophys. Res.-Sol. Ea., 115, B02102, https://doi.org/10.1029/2008jb006160, 2010.

Jaeger, J. C., Cook, N. G. W., and Zimmerman, R. W.: Fundamentals of rock mechanics, 4th ed., Wiley-Blackwell Publishing, Hoboken, NJ, USA, 2007.

Kvenvolden, K. A.: Gas hydrates - geological perspective and global change, Rev. Geophys., 31, 173-187, https://doi.org/10.1029/93RG00268, 1993.

Li, F. G., Sun, C. Y., Zhang, Q., Liu, X. X., Guo, X. Q., and Chen, G. J.: Laboratory Measurements of the Effects of Methane/Tetrahydrofuran Concentration and Grain Size on the P-Wave Velocity of Hydrate-Bearing Sand, Energ. Fuels, 25, 2076-2082, 2011.

Liang, S. and Kusalik, P. G.: The mobility of water molecules through gas hydrates, J. Am. Chem. Soc., 133, 1870-1876, https://doi.org/10.1021/ja108434h, 2011.

Marín-Moreno, H., Sahoo, S. K., and Best, A. I.: Theoretical modeling insights into elastic wave attenuation mechanisms in marine sediments with pore-filling methane hydrate, J. Geophys. Res.Sol. Ea., 60, 1835-1847, https://doi.org/10.1002/2016JB013577, 2017.

Marone, F. and Stampanoni, M.: Regridding reconstruction algorithm for real-time tomographic imaging, J. Synchrotron Radiat., 19, 1029-1037, 2012.

Mavko, G. and Jizba, D.: Estimating grain-scale fluid effects on velocity dispersion in rocks, Geophysics, 56, 1940-1949, https://doi.org/10.1190/1.1443005, 1991.

Müller, T. M., Gurevich, B., and Lebedev, M.: Seismic wave attenuation and dispersion resulting from wave-induced flow in porous rocks - A review, Geophysics, 75, 75A147-75A164, https://doi.org/10.1190/1.3463417, 2010.
Murphy, W. F., Winkler, K. W., and Kleinberg, R. L.: Acoustic relaxation in sedimentary rocks, dependence on grain contacts and fluid saturation, Geophysics, 51, 757-766, https://doi.org/10.1190/1.1442128, 1986.

Nixon, M. F. and Grozic, J. L.: Submarine slope failure due to gas hydrate dissociation: a preliminary quantification, Can. Geotech. J., 44, 314-325, 2007.

O'Connell, R. J. and Budiansky, B.: Viscoelastic properties of fluidsaturated cracked solids, J. Geophys. Res.-Sol. Ea., 82, 57195735, https://doi.org/10.1029/JB082i036p05719, 1977.

Pimienta, L., Fortin, J., and Guéguen, Y.: Bulk modulus dispersion and attenuation in sandstones, Geophysics, 80, D111-D127, https://doi.org/10.1190/geo2014-0335.1, 2015.

Priest, J. A., Best, A. I., and Clayton, C. R. I.: Attenuation of seismic waves in methane gas hydrate-bearing sand, Geophys. J. Int., 164, 149-159, 2006.

Priest, J. A., Rees, E. V. L., and Clayton, C. R. I.: Influence of gas hydrate morphology on the seismic velocities of sands, J. Geophys. Res.-Sol. Ea., 114, B11205, https://doi.org/10.1029/2009jb006284, 2009.

Quintal, B., Jänicke, R., Rubino, J. G., Steeb, H., and Holliger, K.: Sensitivity of S-wave attenuation to the connectivity of fractures in fluid-saturated rocks, Geophysics, 79, WB15-WB24, https://doi.org/10.1190/geo2013-0409.1, 2014.

Quintal, B., Rubino, J. G., Caspari, E., and Holliger, K.: A simple hydromechanical approach for simulating squirt-type flow, Geophysics, 81, D335-D344, https://doi.org/10.1190/geo20150383.1, 2016.

Sams, M. S., Neep, J. P., Worthington, M. H., and King, M. S.: The measurement of velocity dispersion and frequency-dependent intrinsic attenuation in sedimentary rocks, Geophysics, 62, 14561464, https://doi.org/10.1190/1.1444249, 1997.

Schicks, J. M., Spangenberg, E., Giese, R., Steinhauer, B., Klump, J., and Luzi, M.: New Approaches for the Production of Hydrocarbons from Hydrate Bearing Sediments, Energies, 4, 151-172, 2011.

Schicks, J. M., Spangenberg, E., Giese, R., Luzi-Helbing, M., Priegnitz, M., and Beeskow-Strauch, B.: A Counter-Current HeatExchange Reactor for the Thermal Stimulation of HydrateBearing Sediments, Energies, 6, 3002-3016, 2013.

Sell, K., Saenger, E. H., Falenty, A., Chaouachi, M., Haberthür, D., Enzmann, F., Kuhs, W. F., and Kersten, M.: On the path to the digital rock physics of gas hydrate-bearing sediments - processing of in situ synchrotron-tomography data, Solid Earth, 7, 12431258, https://doi.org/10.5194/se-7-1243-2016, 2016.

Sloan, E. D. and Koh, C. A.: Clathrate hydrates of natural gases, 3rd edn., CRC Press, Boca Raton, USA, 2008.

Spangenberg, E. and Kulenkampff, J.: Influence of methane hydrate content on electrical sediment properties, Geophys. Res. Lett., 33, L24315, https://doi.org/10.1029/2006g1028188, 2006

Spangenberg, E., Priegnitz, M., Heeschen, K., and Schicks, J. M.: Are Laboratory-Formed Hydrate-Bearing Systems Analogous to Those in Nature?, J. Chem. Eng. Data, 60, 258-268, 2015.

Subramaniyan, S., Quintal, B., Madonna, C., and Saenger, E. H.: Laboratory-based seismic attenuation in Fontainebleau sandstone: Evidence of squirt flow, J. Geophys. Res.-Sol. Ea., 120, 7526-7535, https://doi.org/10.1002/2015JB012290, 2015.

Tisato, N. and Quintal, B.: Measurements of seismic attenuation and transient fluid pressure in partially saturated Berea sandstone: ev- 
idence of fluid flow on the mesoscopic scale: Geophys. J. Int., 195, 342-351, https://doi.org/10.1093/gji/ggt259, 2013.

Tisato, N. and Quintal, B.: Laboratory measurements of seismic attenuation in sandstone: Strain versus fluid saturation effects, Geophysics, 79, WB9-WB14, https://doi.org/10.1190/geo20130419.1, 2014.

Tohidi, B., Anderson, R., Clennell, M. B., Burgass, R. W., and Biderkab, A. B.: Visual observation of gas-hydrate formation and dissociationin synthetic porous media by means of glass micromodels, Geology, 29, 867-870, https://doi.org/10.1130/00917613(2001)029<0867:VOOGHF>2.0.CO;2, 2001.

Waite, W. F., Santamarina, J. C., Cortes, D. D., Dugan, B., Espinoza, D. N., Germaine, J., Jang, J., Jung, J. W., Kneafsey, T. J., Shin, H., Soga, K., Winters, W. J., and Yun, T. S.: Physical properties of hydrate-bearing sediments, Rev. Geophys., 47, RG4003, https://doi.org/10.1029/2008rg000279, 2009

White, J. E.: Computed seismic speeds and attenuation in rocks with partial gas saturation, Geophysics, 40, 224-232, https://doi.org/10.1190/1.1440520, 1975.
White, J. E., Mikhaylova, N. G., and Lyakhovitskiy, F. M.: Lowfrequency seismic waves in fluid-saturated layered rocks, Izv.Phys. Solid Eart., 11, 654-659, 1975.

Winkler, K. W. and Nur, A.: Seismic attenuation: Effects of pore fluids and frictional-sliding, Geophysics, 47, 1-15, https://doi.org/10.1190/1.1441276, 1982.

Yun, T. S., Francisca, F. M., Santamarina, J. C., and Ruppel, C.: Compressional and shear wave velocities in uncemented sediment containing gas hydrate, Geophys. Res. Lett., 32, L10609, https://doi.org/10.1029/2005GL022607, 2005.

Zhang, Q., Li, F. G., Sun, C. Y., Li, Q. P., Wu, X. Y., Liu, B., and Chen, G. J.: Compressional wave velocity measurements through sandy sediments containing methane hydrate, Am. Mineral., 96, 1425-1432, 2011 